\title{
PENGARUH KOMITMEN ORGANISASIONAL, LINGKUNGAN KERJA, DAN KEPUASAN KERJA TERHADAP TURNOVER INTENTION KARYAWAN KOPERASI PASAR SRINADI
}

\author{
Ni Wayan Meriandayani ${ }^{1}$ \\ Made Subudi ${ }^{2}$ \\ ${ }^{1,2}$ Fakultas Ekonomi dan Bisnis Universitas Udayana (Unud), Bali, Indonesia \\ email: merryandayani517@gmail.com
}

\begin{abstract}
ABSTRAK
Turnover intentions ialah keinginan untuk berpindah ke perusahaan lain namun belum sampai pada tahap realisasi. Faktor-faktor yang menjadi penyebab adanya keinginan untuk pindah kerja (turnover intention) antara lain lingkungan kerja, kepuasan kerja, dan komitmen organisasional. Tujuan penelitian ini adalah untuk menguji pengaruh komitmen organisasional, lingkungan kerja, dan kepuasan kerja terhadap turnover intention. Penelitian ini dilakukan terhadap karyawan Koperasi Pasar Srinadi Klungkung. Populasi dalam penelitian ini sebanyak 298 dengan sampel 75 responden melalui proportionate random sampling. Metode pengumpulan data melalui wawancara dan kuesioner. Teknik analisis data yang digunakan adalah Analisis Regresi Liner Berganda. Hasil penelitian menunjukkan bahwa variabel komitmen organisasional, lingkungan kerja, dan kepuasan kerja berpengaruh negatif dan signifikan terhadap turnover intention karyawan Koperasi Pasar Srinadi Klungkung. Tingginya komitmen organisasional, lingkungan kerja, dan kepuasan kerja dalam perusahaan mampu menekan tingkat turnover intention karyawan.
\end{abstract}

Kata kunci : komitmen organisasional, lingkungan kerja, kepuasan kerja, turnover intention

\begin{abstract}
Turnover intentions are the desire to move, not yet at the realization stage, namely moving from one workplace to another. The factors that cause turnover intention include work environment, job satisfaction, and organizational commitment. The purpose of this study is to examine the effect of organizational commitment, work environment, and job satisfaction on turnover intention. This research was conducted on employees of Koperasi Pasar Srinadi Klungkung. The population in this study were 298 and sample of 75 respondents was obtained through a proportionate random sampling. Methods of collecting data through interviews and questionnaires. The data analysis technique used is Multiple Linear Regression Analysis. The results showed that the variables of organizational commitment, work environment, and job satisfaction negatively and significantly affected the turnover intention of the Koperasi Pasar Srinadi Klungkung employees. The high organizational commitment, work environment, and job satisfaction in the company can reduce employee turnover intention.
\end{abstract}

Keywords: organizational commitment, work environment, turnover intention, job satisfaction 


\section{PENDAHULUAN}

Bali merupakan wilayah Indonesia yang jumlah penduduknya padat, dan setiap tahunnya jumlah penduduk kian meningkat, Bali tidak dapat lepas dari persoalan ketenagakerjaan. Pada setiap tahunnya tingkat pengangguran di Bali menurun persentasenya, tetapi secara nyata jumlah pengangguran tetap tinggi. Terdapat beberapa masalah ketenagakerjaan yang membawa berbagai persoalan sosial ekonomi, seperti jumlah angkatan kerja yang tidak diimbangi oleh perluasan lapangan kerja, tidak sesuainya pendapatan (gaji) yang diperoleh untuk memenuhi kebutuhan hidup, kualitas tenaga kerja yang perlu ditingkatkan dan persebaran tenaga kerja yang belum merata dipelosok Bali.

Jasa keuangan salah satunya koperasi berada diperingkat lima paling banyak menyerap tenaga kerja di Bali. Koperasi Srinadi Klungkung bergerak dalam bidang usaha pelayanan antara lain; unit simpan pinjam, unit grosir, unit swalayan mini, unit percetakan dan konveksi, unit swalayan bangunan, unit supermarket inti, unit wisata tirta, unit bengkel, dan yang terakhir adalah unit radio. Permasalahan yang terjadi pada Koperasi Pasar Srinadi Klungkung yaitu menurunnya pendapatan dan penjualan yang terjadi dibeberapa unit pada tahun 2015 dan 2016. Data Pendapatan dan Penjualan pada tahun 2015 dan 2016 disajikan pada Tabel 1.

Tabel 1.

Data Penjualan dan Pendapatan Koperasi Pasar Srinadi

\begin{tabular}{|c|c|c|c|c|}
\hline \multirow[t]{2}{*}{ Keterangan } & \multicolumn{4}{|c|}{ Tahun } \\
\hline & & 2015 & & 2016 \\
\hline \multicolumn{5}{|l|}{ Penjualan } \\
\hline \multirow{3}{*}{$\begin{array}{ll}- & \text { Unit Grosir } \\
- & \text { Unit Swalayan Mini } \\
- & \text { Unit Bengkel }\end{array}$} & $\mathrm{Rp}$ & 12.153.691.356 & $\mathrm{Rp}$ & 11.102 .726 .259 \\
\hline & $\mathrm{Rp}$ & 13.566 .742 .390 & $\mathrm{Rp}$ & 12.978 .942 .844 \\
\hline & $\mathrm{Rp}$ & 1.957 .372 .497 & $\mathrm{Rp}$ & 1.913.041.175 \\
\hline \multirow[t]{2}{*}{ Pendapatan } & \multirow{2}{*}{$\mathrm{Rp}$} & \multirow{2}{*}{20.397 .162 .420} & $\mathrm{Rp}$ & 19.140.093.086 \\
\hline & & & $\mathrm{Rp}$ & 1.515 .891 .458 \\
\hline - Unit Simpan Pinjam & $\mathrm{Rp}$ & 1.519 .150 .090 & $\mathrm{Rp}$ & 214.305 .500 \\
\hline $\begin{array}{l}\text { Unit Wisata 11rta } \\
\text { - Unit Bengkel }\end{array}$ & $\mathrm{Rp}$ & 301.517 .500 & & \\
\hline
\end{tabular}

Sumber: Koperasi Srinadi, 2018

Dari data di atas dapat dilihat bahwa pada tahun 2016 penjualan unit grosir, swalayan mini dan jasa bengkel mengalami penurunan dari pada tahun 2015. Pada 2016 pendapatan unit simpan pinjam, wisata tirta dan jasa bengkel juga mengalami penurunan dibandingkan 2015.

Tingkat pendapatan yang paling mengalami penurunan yaitu pendapatan unit jasa simpan pinjam yaitu sekitar Rp 1.257.069.334, menurunnya pendapatan unit jasa simpan pinjam dipengaruhi oleh adanya dampak kredit macet sehingga kesempatan koperai dalam mendapatkan laba akan hilang. Dengan adanya masalah seperti penurunan penjualan dan pendapatan tentunya dapat mempengaruhi karyawan berkeinginan untuk meninggalkan Koperasi Pasar Srinadi Klungkung.

Dengan adanya masalah seperti penurunan penjualan dan pendapatan tentunya dapat mempengaruhi karyawan berkeinginan untuk meninggalkan 
Koperasi Pasar Srinadi Klungkung, kenyataannya pada tahun 2017 tingginya tingkat turnover yang mencapai 16,66 persen dan hanya mampu mempertahankan karyawannya sebesar 83,34 persen. Hal tersebut menunjukkan bahwa perusahaan kurang mampu mempertahankan karyawannya agar bisa lebih lama berada di dalam perusahaan.

Gillies (1989) menyatakan perputaran karyawan dikatakan normal berkisar antara 5-10 persen pertahun dan dikatakan tinggi apabila lebih dari 10 persen pertahun. Tingkat perputaran karyawan Koperasi Pasar Srinadi Klungkung menunjukan angka di atas batas normal, kenyataannya pada tahun 2017 tingkat turnover telah mencapai 16,66 persen serta hanya mampu mempertahankan karyawannya sebesar 83,34 persen. Hal ini memperlihatkan bahwa perusahaan memiliki kemampuan untuk yang kurang baik dalam menahan pekerjanya agar lebih lama bekerja di dalam perusahaan. Data Turnover Karyawan Koperasi Pasar Srinadi Tahun 2017 disajikan dalam Tabel 2.

Tabel 2.

Data Turnover Karyawan Koperasi Pasar Srinadi Klungkung Tahun 2017

\begin{tabular}{cccccc}
\hline Bulan & $\begin{array}{c}\text { Jumlah } \\
\text { karyawan } \\
\text { awal bulan } \\
\text { (orang) } \\
(\mathbf{1})\end{array}$ & $\begin{array}{c}\text { Jumlah } \\
\text { karyawan } \\
\text { akhir bulan } \\
\text { (orang) }\end{array}$ & $\begin{array}{c}\text { Rata-rata } \\
\text { karyawan } \\
(\mathbf{( 2 )})\end{array}$ & $\begin{array}{c}\text { Karyawan } \\
\text { keluar } \\
\text { (orang) } \\
\mathbf{( 4 )}\end{array}$ & $\begin{array}{c}\text { Karyawan } \\
\text { keluar (\%) } \\
\mathbf{( 5 ) = ( 4 ) : ~} \\
\mathbf{( 3 ) \times ~ 1 0 0 \%}\end{array}$ \\
\hline Januari & 291 & 291 & 291 & 0 & $0 \%$ \\
Februari & 291 & 290 & 290,5 & 1 & $3,44 \%$ \\
Maret & 290 & 285 & 287.5 & 5 & $1,73 \%$ \\
April & 285 & 279 & 282 & 6 & $2,12 \%$ \\
Mei & 279 & 270 & 274.5 & 9 & $3,27 \%$ \\
Juni & 270 & 268 & 269 & 2 & $0,74 \%$ \\
Juli & 268 & 260 & 264 & 8 & $3,03 \%$ \\
Agustus & 260 & 257 & 258.5 & 3 & $1,16 \%$ \\
September & 257 & 256 & 256.5 & 1 & $0,38 \%$ \\
Oktober & 256 & 256 & 256 & 0 & $0 \%$ \\
November & 256 & 255 & 255.5 & 1 & $0,39 \%$ \\
Desember & 255 & 245 & 250 & 1 & $0,4 \%$ \\
\hline Sumber: Koperasi Pasar Srinadi Klungkung, 2018 & & &
\end{tabular}

Berdasarkan data di atas dapat diketahui dimana selama jangka waktu selama setahun yaitu sejak Januari sampai pada Desember 2017, tingkat perputaran pada karyawan Koperasi Pasar Srinadi Klungkung terbilang tinggi, hal tersebut terlihat pada adanya karyawan yang resign hampir setiap bulan, yang dimana turnover paling tinggi terjadi pada bulan Mei 2017 yaitu 9 orang yang keluar dari perusahaan.

Dapat dikemukakan simpulan bahwa terdapat indikasi masalah turnover karyawan dalam tingkat yang cukup serius dimana bisa menimbulkan efek yang kurang baik bagi Koperasi Pasar Srinadi, seperti dapat menyebabkan terjadi pemborosan selama kegiatan perekrutan dan pelatihan karyawan baru. Adanya tingkat perputaran karyawan yang tinggi pada 2017 menyebabkan adanya kemungkinan peningkatan keinginan karyawan untuk keluar pada tahun berikutnya pada karyawan Koperasi Pasar Srinadi Klungkung. 
Tingkat keinginan melakukan perpindahn yang tinggi pada karyawan dapat diakibatkkan oleh sejumlah variabel antara lain kepuasankerja, komitmen organisasional, lingkungan kerja.

Berdasarkan permasalahan yang telah ditemukan, maka akan dirumuskan masalah penelitian sebagai berikut : 1) Apakah komitmen organisasional berpengaruh terhadap turnover intention karyawan pada Koperasi Pasar Srinadi Klungkung? 2) Apakah lingkungan kerja berpengaruh terhadap turnover intention karyawan pada Koperasi Pasar Srinadi Klungkung? 3) Apakah kepuasan kerja berpengaruh terhadap turnover intention karyawan pada Koperasi Pasar Srinadi Klungkung?

Berdasarkan perumusan masalah di atas, maka dapat dikemukakan tujuan dari penelitian ini adalah sebagai berikut : 1) Untuk menganalisis pengaruh komitmen organisasional terhadap turnover intention karyawan pada Koperasi Pasar Srinadi Klungkung. 2) Untuk menganalisis pengaruh lingkungan kerja terhadap turnover intention karyawan pada Koperasi Pasar Srinadi Klungkung. 3) Untuk menganalisis pengaruh kepuasan kerja terhadap turnover intention karyawan pada Koperasi Pasar Srinadi Klungkung.

Hasil dari penelitian ini diharapkan mampu memberikan manfaat yang tidak hanya untuk penelitian tetapi juga kepada lembaga pendidikan dan pihak lain yang ikut serta berkepentingan dengan penelitian ini. Dari hasil penelitian ini diharapkan memiliki manfaat dan dapat menambah pengetahuan dibidang ilmu manajemen sumber daya manusia, khususnya dalam kajian tentang aspek komitmen organisasional, lingkungan kerja, kepuasan kerja, dan turnover intention.

Hasil dari penelitian ini diharapkan dapat memberikan manfaat dan sebagai bahan pertimbangan perusahaan dalam mengambil keputusan-keputusan yang berkaitan dengan komitmen organisasional, lingkungan kerja, dan kepuasan kerja serta pengaruhnya terhadap turnover intention, sehinga diharapkan dapat dilakukan pencegahan terjadinya turnover yang merugikan perusahaan.

Teori yang mendasari penelitian ini adalah teori pertukaran sosial yang pertama kali dikemukakan oleh George C Homans yang dikembangkan oleh Peter Blau. Awalnya teori ini hanya menitik beratkan pada hubungan antar individu, kemudian dikembangkan oleh Blau menjadi lebih luas yaitu antara indivisu dengan kelompok. Teori ini didasarkan pada hubungan yang semakin erat sampai pada saling percaya, loyal, dan saling berkomitmen antara kedua belah pihak. Teori pertukaran sosial (Social Exchange Theory) merupakan pandangan karyawan ketika mereka telah diperlakukan dengan baik oleh organisasi, mereka akan cenderung untuk melakukan balas budi terhadap organisasi dengan bersikap dan berperilaku positif, dimana ketika karyawan telah puas terhadap pekerjaannya, mereka akan membalasnya, pembalasan dari karyawan tersebut, termasuk perasaan memiliki yang kuat terhadap organisasi.

Pergantian karyawan atau keluar masuknya karyawan dari organisasi adalah suatu fenomena penting dalam kehidupan organisasi. Turnover intentions adalah keinginan untuk berpindah, belum sampai pada tahap realisasi yaitu melakukan perpindahan dari satu tempat kerja ke tempat kerja lainnya. Indikasi adanya niatan itu muncul dalam bentuk perilaku karyawan, antara lain: absensi yang meningkat, mulai malas kerja, naiknya keberanian untuk melanggar tata tertib kerja, keberanian 
untuk menentang atau protes kepada atasan, maupun keseriusan untuk menyelesaikan semua tanggung jawab karyawan yang sangat berbeda dari biasanya (Widyadmono, 2015)

Bramantara \& Dewi (2015) menyebutkan turnover intention adalah kadar atau intensitas dari keinginan karyawan untuk keluar dari perusahaan. Selanjutnya, Bluedorn dalam Widodo (2010) menyatakan bahwa turnover intention adalah kecenderungan sikap atau tingkat dimana seorang karyawan memiliki kemungkinan untuk meninggalkan organisasi atau mengundurkan diri secara sukarela dari pekerjaannya.

Faktor yang menyebabkan karyawan berpindah pekerjaan dapat kategorikan sebagai faktor eksternal dan faktor internal. Faktor eksternal berupa pendorong yang berasal dari luar individu karyawan, seperti dorongan keluarga dan peluang yang diberikan perusahaan lain. Faktor internal adalah faktor yang terkait langsung dengan diri karyawan, seperti karakter individu yang memengaruhi keinginan pindah kerja antara lain usia, pendidikan, dan keluarga. Lingkungan kerja dapat meliputi lingkungan fisik maupun non fisik; Lingkungan fisik meliputi keadaan suhu, cuaca, konstruksi, bangunan, dan lokasi pekerjaan. Adapun lingkungan non fisik meliputi sosial budaya di lingkungan kerjanya dan kualitas kehidupan kerjanya; Aspek kepuasan meliputi kepuasan akan gaji dan promosi, kepuasan atas supervisor yang diterima, kepuasan dengan rekan kerja dan kepuasan akan pekerjaan dan isi kerja; komitmen organisasional sebagai konsep yang turut menjelaskan proses tersebut sebagai bentuk perilaku, komitmen organisasional dapat dibedakan dari kepuasan kerja.

Penelitian yang dilakukan Widyantara \& Ardana (2015), Rarasanti \& Suana (2016) , Abdurrahim \& Anisah (2015), Youcef et al. (2016), Jehanzeb et al. (2013), Handaru \& Muna (2012), Salleh et al. (2012), Sutanto \& Gunawan (2013), dan Susila Putra \& Suana (2016) memperlihatkan komitmen organisasional memiliki perngaruh yang negatif dan signifikan terhadap turnover intention. Semakin tinggi komitmen organisasional, maka keinginan keluar akan semakin turun. Nilesh (2015) meneliti hubungan komitmen organisasional terhadap turnover intention menemukan hubungan negatif antara turnover intention dengan komitmen organisasional, dimana terapat indikasi turnover intention yang tinggi menandakan komitmen yang rendah.

$\mathrm{H}_{1}$ : Komitmen organisasional berpengaruh secara negatif dan signifikan terhadap turnover intention .

Qureshi et al. (2013) menemukan lingkungan kerja mempunyai pengaruh negatif terhadap turnover intention, yang memperlihatkan keadaan kerja yang baik dapat menurunkan turnover intention. Ia mendapati lingkungan kerja secara parsial mempunyai pengaruh yang negatif pada variabel turnover intention, semakin nyaman lingkungan yang diperoleh karyawan maka turnover intention karyawan akan semakinrendah.

Lingkungan kerja mempunyai hubungan negatif pada turnover intention, yaitu saat lingkungan kerja di sebuah perusahaan dalam kondisi yang tidak kondusif untuk melaksanakan tugas seperti pencahayaan yang cukup dan keamanann di tempat kerja yang terjamin sehingga bisa dipastikan karyawan tidak bisa bertahan 
lama di perusahaan itu dan sehingga dikatakan turnover intention akan semakin meiningikat.

Chairani (2014) juga menemukan bahwa lingkungan kerja mempunyai dampak negatif terhadap turnover intention dimana lingkungan kerja yang kurang baik, seperti fasilitas yang diterima karyawan tidak mencukupi, tidak tersedianya tempat untuk istirahat karyawan, membuat niat karyawan untuk mengundurkan diri.

$\mathrm{H}_{2}$ : Lingkungan kerja berpengaruh secara negatif dan signifikan terhadap turnover intention.

Khan et al. (2014) menyatakan bahwa kepuasan kerja memberikan pengaruh yang negatif terhadap turnover intention. Semakin tinggi kepuasan karyawan dalam organisasi maka niat karyawan untuk meninggalkan organisasi akan rendah. Bila karyawan tidak merasakan rasa puas terhadap pekerjaannya, maka mereka akan cenderung untuk meninggalkan organisasinya, serta kebalikannya jika karyawan tersebut mendapat perlakuan yang adil dan memperoleh kompensasi yang sesuai dengan yang mereka harapkan maka karyawan tersebut tidak akan meninggalkan organisasinya.

Kepuasan kerja mempunyai hubungan negatif serta signifikan pada turnover intention hal ini memunculkan indikasi bahwa puas atau tidaknya karyawan bisa memberikan pengaruh pada perilaku karyawan untuk pergi meninggalkan perusahaan. Studi sebelumnya juga telah mendapatkan hasil yang sama (Mahdi et al., 2012). Kepuasaan kerja mempunyai hubungan yang negatif terhadap hasrat berpindah kerja karyawan (turnover intention) yang memunculkan indikasi bahwa kepuaasan kerja yang rendah mepengaruhi tingginya turnover intention

$\mathrm{H}_{3}$ : Kepuasan kerja berpengaruh secara negatif dan signifikan terhadap turnover intention.

\section{METODE PENELITIAN}

Pendekatan kuantitatif-asosiatif dipergunakan untuk menganalisis data yang statistik degan kuesioner sebagai instrumen yang dipakai. Lokasi penelitian bertempat di Koperasi Pasar Srinadi Klungkung di Jalan Mahoni, Semarapura Klod, Klungkung. Dipilihnya lokasi untuk peneliti melakukan penelitian di Koperasi Pasar Srinadi adalah adanya masalah tingginya tingkat turnover dan rendahnya tingkat turnover intention. Obyek dari penelitian ini adalah 1) komitmen organisasional, 2) lingkungan kerja, 3) kepuasan kerja, 4) turnover intention. Variabel terikat, yaitu variabel yang dipengaruhi oleh adanya variabel bebas. Dalam penelitian ini yang menjadi variabel terikat adalah turnover intetion (Y). Variabel bebas, yaitu variabel yang dapat mempengaruhi atau merubah variabel terikat. Dalam penelitian ini, variabel bebas adalah komitmen organisasional $\left(\mathrm{X}_{1}\right)$, lingkungan kerja $\left(\mathrm{X}_{2}\right)$, kepuasan kerja $\left(\mathrm{X}_{3}\right)$

Data kuantitatif adalah, data absensi karyawan. Data kuantitatif yang digunakan ialah jumlah karyawan dan data turnover karyawan yang diperoleh dari Koperasi Pasar Srinadi Klungkung. Data kualitatif pada penelitian ini adalah sejarah perusahaan dan struktur organisasi yang diperoleh dari Koperasi Pasar Srinadi Klungkung. Sumber primer merupakan data yang diperoleh langsung dari 
responden melalui pemberian kuesioner. Data sekunder yang dipergunakann ialah sejarah perusahaan dan jumlah karyawan.

Populasi yang dipergunakan adalah seluruh karyawan Koperasi Pasar Srinadi Klungkung yang berjumlah 298 orang. Jumlah sampel Koperasi Pasar Srinadi Klungkung yang diambil dalam penelitian ini yaitu sebanyak 75 sampel dengan menggunakan teknik proportionate random sampling. Pengumpulan data yang dipergunakan ialah metode wawancara dan kuesioner

\section{HASIL DAN PEMBAHASAN}

Data dikumpulkan dengan cara menyebarkan kuesioner ke Koperasi Pasar Srinadi Klungkung. Kuesioner disebarkan sebanyak 75 kuesioner. Sebagian besar responden dalam penelitian ini berusia 20 sampai 29 tahun dengan persentase sebesar 52\% atau sebanyak 39 orang yang merupakan kelompok dalam usia produktif yang mampu bekerja dengan baik. Penelitian ini didominasi dengan responden berjenis kelamin perempuan dengan persentase sebesar 56\% atau 42 orang dan sisanya sebesar $44 \%$ atau 33 orang berjenis kelamin laki-laki. Hasil ini menunjukkan bahwa Koperasi Pasar Srinadi Klungkung lebih banyak membutuhkan tenaga perempuan karena lebih banyak berkaitan dengan pekerjaan pelayanan konsumen dan administrasi. Pendidikan terakhir responden sebagian besar merupakan lulusan SMA/SMK dengan persentase sebesar 90,67 atau 68 orang, seseorang yang sudah menempuh pendidikan hingga jenjang SMA diasumsikan memiliki pemahaman dan kemampuan yang cukup baik dalam menyelesaikan pekerjaan. Divisi pekerjaan responden terbanyak yaitu pada divisi supermarket inti, karena memiliki jumlah karyawan terbesar, yaitu sebanyak 66 karyawan

Tabel 3.

Rekapitulasi Hasil Uji Reliabilitas Instrumen Penelitian

\begin{tabular}{cccc}
\hline No. & Variabel & Cronbach's Alpha & Keterangan \\
\hline $\mathbf{1}$ & Komitmen organisasional $\left(\mathrm{X}_{1}\right)$ & 0,768 & Reliabel \\
$\mathbf{2}$ & Lingkungan kerja $\left(\mathrm{X}_{2}\right)$ & 0,855 & Reliabel \\
$\mathbf{3}$ & Kepuasan kerja $\left(\mathrm{X}_{3}\right)$ & 0,788 & Reliabel \\
$\mathbf{4}$ & Turnover intention $(\mathrm{Y})$ & 0,864 & Reliabel \\
\hline
\end{tabular}

Sumber: Data diolah, 2018

Hasil pengujian reliabilitas yang ditampilkan pada Tabel 3 menunjukkan bahwa variabel penelitian mempunyai nilai Cronbach's Alpha lebih dari 0,60 yang mana dapat dinyatakan bahwa keseluruhan variabel sudah mencukupi syarat reliabilitas atau kehandalan kemudian daepat digunakan untuk dianalisis lebih lanjut.

Hasil pengujian validitas pada Tabel 4 memperlihatkan indikator yang dipergunakan untuk menganalisis variable komitmen organisasional, lingkungan kerja, kepuasan kerja, dan turnover intention memiliki nilai koefisien korelasi dengan skor total seluruh butir pernyataan lebih besar dari 0,30 dengan signifikansi kurang dari 0,05 . 
Tabel 4.

Rekapitulasi Hasil Uji Validitas Instrumen Penelitian

\begin{tabular}{|c|c|c|c|c|}
\hline Variabel & Indikator & Koefisien Korelasi & Sig. (2-tailed) & Keterangan \\
\hline \multirow{8}{*}{$\begin{array}{c}\text { Komitmen } \\
\text { organisasional } \\
\left(\mathrm{X}_{1}\right)\end{array}$} & $\mathrm{X}_{1.1}$ & 0,527 & 0,003 & Valid \\
\hline & $\mathrm{X}_{1.2}$ & 0,841 & 0,000 & Valid \\
\hline & $\mathrm{X}_{1.3}$ & 0,699 & 0,000 & Valid \\
\hline & $\mathrm{X}_{1.4}$ & 0,781 & 0,000 & Valid \\
\hline & $\mathrm{X}_{1.5}$ & 0,520 & 0,000 & Valid \\
\hline & $\mathrm{X}_{1.6}$ & 0,610 & 0,000 & Valid \\
\hline & $\mathrm{X}_{1.7}$ & 0,860 & 0,000 & Valid \\
\hline & $\mathrm{X}_{1.8}$ & 0,607 & 0,000 & Valid \\
\hline \multirow{12}{*}{$\begin{array}{l}\text { Lingkungan kerja } \\
\qquad\left(\mathrm{X}_{2}\right)\end{array}$} & $\mathrm{X}_{2.1}$ & 0,626 & 0,000 & Valid \\
\hline & $\mathrm{X}_{2.2}$ & 0,745 & 0,000 & Valid \\
\hline & $\mathrm{X}_{2.3}$ & 0,545 & 0,002 & Valid \\
\hline & $\mathrm{X}_{2.4}$ & 0,569 & 0,001 & Valid \\
\hline & $\mathrm{X}_{2.5}$ & 0,736 & 0,000 & Valid \\
\hline & $\mathrm{X}_{2.6}$ & 0,507 & 0,004 & Valid \\
\hline & $\mathrm{X}_{2.7}$ & 0,373 & 0,042 & Valid \\
\hline & $\mathrm{X}_{2.8}$ & 0,417 & 0,022 & Valid \\
\hline & $\mathrm{X}_{2.9}$ & 0,505 & 0,004 & Valid \\
\hline & $\mathrm{X}_{2.10}$ & 0,493 & 0,006 & Valid \\
\hline & $\mathrm{X}_{2.11}$ & 0,403 & 0,027 & Valid \\
\hline & $\mathrm{X}_{2.12}$ & 0,486 & 0,006 & Valid \\
\hline \multirow{7}{*}{$\begin{array}{l}\text { Kepuasan kerja } \\
\qquad\left(\mathrm{X}_{3}\right)\end{array}$} & $\mathrm{X}_{3.1}$ & 0,706 & 0,000 & Valid \\
\hline & $\mathrm{X}_{3.2}$ & 0,838 & 0,000 & Valid \\
\hline & $\mathrm{X}_{3.3}$ & 0,765 & 0,000 & Valid \\
\hline & $\mathrm{X}_{3.4}$ & 0,530 & 0,003 & Valid \\
\hline & $\mathrm{X}_{3.5}$ & 0,602 & 0,000 & Valid \\
\hline & $\mathrm{X}_{3.6}$ & 0,616 & 0,000 & Valid \\
\hline & $\mathrm{X}_{3.7}$ & 0,505 & 0,004 & Valid \\
\hline \multirow{5}{*}{$\begin{array}{l}\text { Turnover intention } \\
\text { (Y) }\end{array}$} & $\mathrm{Y}_{1}$ & 0,809 & 0,000 & Valid \\
\hline & $\mathrm{Y}_{2}$ & 0,813 & 0,000 & Valid \\
\hline & $Y_{3}$ & 0,750 & 0,000 & Valid \\
\hline & $\mathrm{Y}_{4}$ & 0,694 & 0,000 & Valid \\
\hline & $Y_{5}$ & 0,663 & 0,000 & Valid \\
\hline
\end{tabular}

Sumber: Data diolah, 2018

Hasil kuesioner yang diisi oleh karyawan Koperasi Pasar Srinadi Klungkung menunjukkan rata-rata keseluruhan indikator yaitu 3,28 yang termasuk dalam kriteria cukup. Hal ini membuktikan bahwa karyawan Koperasi Pasar Srinadi Klungkung, merasa cukup berkeinginan untuk meninggalkan perusahaan.Nilai rerata tertinggi jawaban responden diperlihatkan pada pernyataan "Saya tertarik untuk mencari lowongan pekerjaan lainnya.", dengan nilai rerata 3,53 yang berarti termasuk tinggi ini menunjukkan bahwa karyawan pada Koperasi Pasar Srinadi Klungkung memiliki ketertarikan untuk mencari lowongan pekerjaan lainnya. 
Tabel 5.

Deskripsi Jawaban Responden Mengenai Variabel Turnover Intention

\begin{tabular}{|c|c|c|c|c|c|c|c|c|c|}
\hline \multirow[t]{3}{*}{ No } & \multirow[t]{3}{*}{ Pernyataan } & \multicolumn{5}{|c|}{ Skor Jawaban } & \multirow{3}{*}{$\begin{array}{l}\text { Jumlah } \\
\text { Skor }\end{array}$} & \multirow{3}{*}{$\begin{array}{l}\text { Rata- } \\
\text { Rata }\end{array}$} & \multirow[t]{3}{*}{ Ket } \\
\hline & & \multirow{2}{*}{$\begin{array}{c}\text { STS } \\
1\end{array}$} & \multirow{2}{*}{$\begin{array}{c}\text { TS } \\
2\end{array}$} & \multirow{2}{*}{$\begin{array}{l}\mathbf{N} \\
3\end{array}$} & \multirow{2}{*}{$\begin{array}{l}S \\
4\end{array}$} & \multirow{2}{*}{$\begin{array}{c}S S \\
5\end{array}$} & & & \\
\hline & & & & & & & & & \\
\hline 1. & $\begin{array}{l}\text { Saya sering berfikir untuk } \\
\text { berhenti bekerja }\end{array}$ & 0 & 17 & 33 & 21 & 4 & 237 & 3,16 & Cukup \\
\hline 2. & $\begin{array}{l}\text { Saya sering berfikir untuk } \\
\text { meninggalkan Koperasi } \\
\text { Pasar Srinadi Klungkung. }\end{array}$ & 1 & 14 & 34 & 24 & 2 & 237 & 3,16 & Cukup \\
\hline 3. & $\begin{array}{l}\text { Saya tertarik untuk } \\
\text { mencari lowongan } \\
\text { pekerjaan lainnya. }\end{array}$ & 0 & 8 & 29 & 28 & 10 & 265 & 3,53 & Tinggi \\
\hline 4. & $\begin{array}{l}\text { Saya akan sukarela } \\
\text { meninggalkan Koperasi } \\
\text { Pasar Srinadi Klungkung } \\
\text { dalam waktu } 3 \text { bulan } \\
\text { kedepan. }\end{array}$ & 0 & 10 & 41 & 22 & 2 & 241 & 3,21 & Cukup \\
\hline 5. & $\begin{array}{l}\text { Saya tidak berharap masa } \\
\text { depan yang panjang } \\
\text { dengan Koperasi Pasar } \\
\text { Srinadi Klungkung. }\end{array}$ & 0 & 10 & 34 & 26 & 5 & 251 & 3,35 & Tinggi \\
\hline & Tur & over I & tenti & & & & & 3,28 & Cukup \\
\hline
\end{tabular}

Sumber: Hasil data diolah, 2018

Nilai rerata terendah jawaban responden ditunjukkan pada pernyataan pertama "Saya sering berfikir untuk berhenti bekerja." dan yang kedua "Saya sering berfikir untuk meninggalkan Koperasi Pasar Srinadi Klungkung." Dengan nilai rata-rata sebesar 3,16 yang berarti masuk dalam kriteria cukup ini menunjukkan bahwa karyawan Koperasi Pasar Srinadi cukup ingin berhenti bekerja dan cukup berfikir untuk meninggalkan Koperasi Pasar Srinadi Klungkung.

Hasil kuesioner yang diisi oleh karyawan Koperasi Pasar Srinadi Klungkung menunjukkan rata-rata keseluruhan indikator yaitu sebesar 3,82 yang berarti termasuk dalam kreteria tinggi. Hal ini menunjukkan bahwa karyawan Koperasi Pasar Srinadi Klungkung, memiliki keinginan dan keyakinan yang tinggi untuk terlibat pada kegiatan dalam perusahaan.

Berdasarkan Tabel 6. nilai rerata terendah jawaban responden ditunjukkan pada pernyataan "Saya berkerja untuk memajukan Koperasi Pasar Srinadi Klungkung." Dengan nilai rerata sebesar 3,60 yang berarti masuk dalam kriteria tinggi ini menunjukkan bahwa karyawan Koperasi Pasar Srinadi berkerja untuk memajukan Koperasi Pasar Srinadi Klungkung. Nilai rerata tertinggi jawaban responden ditunjukkan pada pernyataan "Saya setuju dengan nilai-nilai yang dianut Koperasi Pasar Srinadi Klungkung.”, dengan nilai rata-rata 4,11 yang berarti masuk dalam kriteria tinggi ini menunjukkan bahwa karyawan setuju dengan nilai-nilai yang dianut oleh Koperasi Pasar Srinadi Klungkung. Hasil kuesioner yang diisi oleh karyawan Koperasi Pasar Srinadi Klungkung menunjukkan rata-rata keseluruhan indikator yaitu sebesar 3,92 yang berarti termasuk dalam kreteria tinggi. Hal ini menunjukkan bahwa karyawan Koperasi Pasar Srinadi Klungkung, pelayanan yang 
didapat, kondisi tempat kerja, dan hubungan kerja. Nilai rerata terendah jawaban responden ditunjukkan pada pernyataan "Koperasi Pasar Srinadi Klungkung memberikan program kesehatan dengan baik dan dapat digunakan dengan mudah."

Tabel 6.

Variabel Komitmen Organisasional

\begin{tabular}{|c|c|c|c|c|c|c|c|c|c|}
\hline \multirow{3}{*}{$\begin{array}{l}\mathbf{N} \\
\mathbf{0}\end{array}$} & \multirow[t]{3}{*}{ Pernyataan } & \multicolumn{5}{|c|}{ Skor Jawaban } & \multirow{3}{*}{$\begin{array}{c}\text { Jumlah } \\
\text { Skor }\end{array}$} & \multirow{3}{*}{$\begin{array}{l}\text { Rata- } \\
\text { Rata }\end{array}$} & \multirow[t]{3}{*}{ Ket } \\
\hline & & STS & TS & $\mathbf{N}$ & $\mathbf{S}$ & SS & & & \\
\hline & & 1 & 2 & 3 & 4 & 5 & & & \\
\hline 1. & $\begin{array}{lr}\text { Saya } & \text { bangga } \\
\text { menceritakan } & \text { kepada } \\
\text { orang lain, } & \text { bahwa } \\
\text { Koperasi Pasar } & \text { Srinadi } \\
\text { Klungkung } & \text { adalah } \\
\text { perusahaan yang baik. }\end{array}$ & 0 & 2 & 27 & 37 & 9 & 278 & 3,71 & Tinggi \\
\hline 2. & $\begin{array}{l}\text { Menurut saya, Koperasi } \\
\text { Pasar Srinadi Klungkung } \\
\text { perusahaan yang baik } \\
\text { untuk tempat bekerja. }\end{array}$ & 0 & 5 & 20 & 44 & 6 & 277 & 3,69 & Tinggi \\
\hline 3. & $\begin{array}{l}\text { Koperasi Pasar Srinadi } \\
\text { Klungkung tempat saya } \\
\text { bekerja, membuat saya } \\
\text { termotivasi untuk } \\
\text { berprestasi lebih baik. }\end{array}$ & 0 & 1 & 16 & 51 & 17 & 289 & 3,85 & Tinggi \\
\hline 4. & $\begin{array}{l}\text { Koperasi Pasar Srinadi } \\
\text { Klungkung tempat saya } \\
\text { bekerja, mengispirasi } \\
\text { saya untuk selalu bekerja } \\
\text { keras dalam memajukan } \\
\text { perusahaan. }\end{array}$ & 0 & 1 & 20 & 43 & 11 & 289 & 3,85 & Tinggi \\
\hline 5. & $\begin{array}{l}\text { Saya setuju dengan nilai- } \\
\text { nilai yang dianut } \\
\text { Koperasi Pasar Srinadi } \\
\text { Klungkung. }\end{array}$ & 0 & 0 & 9 & 49 & 17 & 308 & 4,11 & Tinggi \\
\hline 6. & $\begin{array}{l}\text { Nilai-nilai yang saya anut } \\
\text { sama dengan nilai-nilai } \\
\text { dianut Koperasi Pasar } \\
\text { Srinadi Klungkung. }\end{array}$ & 0 & 1 & 9 & 55 & 10 & 299 & 3,99 & Tinggi \\
\hline 7. & $\begin{array}{l}\text { Saya berkerja untuk } \\
\text { memajukan Koperasi } \\
\text { Pasar Srinadi Klungkung. }\end{array}$ & 0 & 6 & 27 & 33 & 9 & 270 & 3,60 & Tinggi \\
\hline \multirow[t]{2}{*}{8.} & $\begin{array}{l}\text { Saya bersedia bekerja } \\
\text { seoptimal mungkin untuk } \\
\text { tercapainya } \\
\text { Koperasi Pasar Srinadi } \\
\text { Klungkung. }\end{array}$ & 0 & 2 & 19 & 45 & 9 & 286 & 3,81 & Tinggi \\
\hline & Komitı & en or & anis & sional & & & & 3,82 & $\begin{array}{c}\text { Tingg } \\
\mathbf{i}\end{array}$ \\
\hline
\end{tabular}


Dengan nilai rata-rata sebesar 3,61 yang berarti masuk dalam kreteria tinggi ini menunjukkkan bahwa karyawan Koperasi Pasar Srinadi sudah mendapatkan program kesehata yang baik dan dapat digunakan dengan mudah. Nilai rerata tertinggi jawaban responden ditunjukkan pada pernyataan "Pengaturan dan pengendalian suara bising di Koperasi Pasar Srinadi Klungkung sudah baik.”, dengan nilai rata-rata 4,24 yang berarti masuk dalam kriteria tinggi ini menunjukkan bahwa karyawan merasa nyaman dan lebih berkonsentari karena adanya pengaturan dan pengendalian suara bising Koperasi Pasar Srinadi Klungkung. Hasil kuesioner yang diisi oleh karyawan Koperasi Pasar Srinadi Klungkung d menunjukkan rata-rata keseluruhan indikator yaitu sebesar 3,86 yang berarti termasuk dalam kreteria tinggi. Hal ini menunjukkan bahwa karyawan Koperasi Pasar Srinadi Klungkung, mendapatkan kepuasan kerja dan hasil kerja.

Nilai rerata terendah jawaban responden ditunjukkan pada pernyataan "Atasan memberikan dukungan kepada saya." Dengan nilai rata-rata sebesar 3,53 yang berarti masuk dalam kriteria tinggi ini menunjukkan bahwa karyawan Koperasi Pasar Srinadi atasan di Koperasi Pasar Srinadi Klungkung memberikan dukungan kepada karyawan. Nilai rerata tertinggi jawaban responden ditunjukkan pada pernyataan "Bilamana dibutuhkan rekan kerja memberikan bantuan langsung untuk menyelesaikan pekerjaan tepat pada waktunya.", dengan nilai rata-rata 4,10 yang berarti masuk dalam kriteria tinggi ini menunjukkan bahwa karyawan Koperasi Pasar Srinadi Klungkung merasa hubungan dengan rekan kerjanya baik, karena saat karyawan meminta rekan keranya untuk mrlakukan pekerjaan tertentu, pekerjaan tersebut selesai.

Nilai rerata tertinggi jawaban responden ditunjukkan pada pernyataan "Saya tertarik untuk mencari lowongan pekerjaan lainnya.", dengan nilai rata-rata 3,53 yang berarti masuk dalam kriteria tinggi ini menunjukkan bahwa karyawan pada Koperasi Pasar Srinadi Klungkung memiliki ketertarikan untuk mencari lowongan pekerjaan lainnya. Selanjutnya, nilai rata-rata terendah jawaban responden ditunjukkan pada pernyataan pertama "Saya sering berfikir untuk berhenti bekerja." dan yang kedua "Saya sering berfikir untuk meninggalkan Koperasi Pasar Srinadi Klungkung." Dengan nilai rata-rata sebesar 3,16 yang berarti masuk dalam kriteria cukup ini menunjukkan bahwa karyawan Koperasi Pasar Srinadi cukupingin berhenti bekerja dan cukup berfikir untuk meninggalkan Koperasi Pasar Srinadi Klungkung.Pada analisis statistik inferensial menggunakan metode regresi linier berganda ini digunakan untuk menganalisis pengaruh komitmen organisasional $\left(\mathrm{X}_{1}\right)$, lingkungan kerja $\left(\mathrm{X}_{2}\right)$, dan kepuasan kerja $\left(\mathrm{X}_{3}\right)$ terhadap turnover intention (Y). Pada Tabel 7 menunjukkan hasil analisis regresi linier berganda sebagai berikut.

Berdasarkan hasil perhitungan analisis linier berganda pada Tabel 7. dapat disusun persamaan regresi sebagai berikut :

$Y=28,836-0,203 X_{1}-0,319 X_{2}-0,288 X_{3}+\varepsilon$

Interpretasi dari persamaan di atas adalah sebagai berikut : Nilai konstanta sebesar 28,836 yaitu jika nilai Komitmen organisasional, lingkungan kerja, dan 
kepuasan kerjasama dengan nol, maka nilai turnover intention adalah sebesar 28,836 .

Koefisein regresi $\left(\beta_{1}\right)$ pada komitmen organisasional $\left(\mathrm{X}_{1}\right)$ mempunyai nilai $-0,203$ serta berhubungan negatif pada turnover intention. Artinya, bila nilai komitmen organisasional $\left(\mathrm{X}_{1}\right)$ bertambah, maka turnover intention $(\mathrm{Y})$ akan terjadi penurunan dengan anggapan variabel bebas lainnya konstan.

Tabel 7.

Hasil Uji Regresi Linear Berganda

\begin{tabular}{llrrrrr}
\hline Model & \multicolumn{2}{c}{$\begin{array}{c}\text { Unstandardized } \\
\text { Coefficients }\end{array}$} & $\begin{array}{c}\text { Standardized } \\
\text { Coefficients }\end{array}$ & & T & Sig. \\
\cline { 3 - 5 } & & B & $\begin{array}{c}\text { Std. } \\
\text { Error }\end{array}$ & Beta & & \\
\hline $1 \quad$ (Constant) & 28.836 & 2.232 & & & \\
& Komitmen organisasional & -.203 & .063 & -.312 & -3.234 & .002 \\
& Lingkungan kerja & -.319 & .083 & -.326 & -3.858 & .000 \\
& Kepuasan kerja & -.288 & .077 & -.356 & -3.717 & .000 \\
\hline
\end{tabular}

Sumber: Data diolah, 2018

Keofisien regresi $\left(\beta_{2}\right)$ pada lingkungan kerja $\left(\mathrm{X}_{2}\right)$ bernilai $-0,319$ mempunyai hubungan negatif pada turnover intention. Artinya, jika nilia lingkungan kerja $\left(\mathrm{X}_{2}\right)$ meningkat, maka turnover intention (Y) akan mengalami penurunan dengan asumsi variabel bebas lainnya konstan.

Koefisien regresi $\left(\beta_{3}\right)$ pada kepuasan kerja $\left(\mathrm{X}_{3}\right)$ bernilai $-0,288$ mempunyai hubungan negatif pada turnover intention. Artinya, bila kepuasan kerja $\left(\mathrm{X}_{3}\right)$ bertambah, maka turnover intention (Y) akan turun dengan asumsi variabel bebas lainnya konstan.

Tabel 8.

Hasil Uji Normalitas

\begin{tabular}{cc}
\hline & Unstandardized Residual \\
\hline $\mathrm{N}$ & 75 \\
Kolmogorov-Smirnov $Z$ & 0,650 \\
Asymp.Sig.(2-tailed) & 0,792 \\
\hline
\end{tabular}

Sumber: Data diolah, 2018

Berdasarkan pengujian normalitas seperti yang terdapat pada Tabel 8 nilai Kolmogorov-Smirnov, memberikan petunjuk bahwa nilai Asymp. Sig (2-tailed) 0,792 lebih besar dari level ofsignificant, yaitu 5 persen $(0,05)$ sehingga data yang diuji tersebar secara normal.

Untuk mendeteksi ada atau tidaknya multikolinearitas pada model regresi dapat dilihat pada nilai tolerance dan nilai variance inflation factor (VIF). Jika nilai tolerance lebih dari 10 persen atau VIF kurang dari 10, maka dikatakan tidak ada multikolinearitas.

Berdasarkan Tabel 9. dapat dikemukakan nilai tolerance diatas $10 \%(0,10)$ dan VIF dibawah 10. Hal ini menunjukkan bahwa model regresi yang ada tidak terjadi gejala multikolinearitas. 
Model regresi yang baik adalah yang tidak mengandung gejala heteroskedastisitas atau mempunyai varians yang homogen. Jika variabel bebas yang diteliti tidak mempunyai pengaruh signifikan atau nilai signifikansinya lebih dari 0,05 terhadap nilai absolute residual, berarti model regresi tidak mengandung gejala heteroskedastisitas. Hasil pengujian heteroskedastisitas disajikan pada Tabel 10.

Tabel 9.

Hasil Uji Multikolinearitas

\begin{tabular}{ccc}
\hline Variabel & Tolerance & VIF \\
\hline Komitmen organisasional $\left(\mathrm{X}_{1}\right)$ & 0,742 & 1,348 \\
Lingkungan kerja $\left(\mathrm{X}_{2}\right)$ & 0,962 & 1,039 \\
Kepuasan kerja $\left(\mathrm{X}_{3}\right)$ & 0,752 & 1,330 \\
\hline
\end{tabular}

Sumber: Data diolah, 2018

Tabel 10.

Hasil Uji Heteroskedastisitas

\begin{tabular}{|c|c|c|c|c|c|c|}
\hline \multirow{2}{*}{\multicolumn{2}{|c|}{ Model }} & \multicolumn{2}{|c|}{$\begin{array}{l}\text { Unstandardized } \\
\text { Coefficients }\end{array}$} & \multirow{2}{*}{$\begin{array}{c}\begin{array}{c}\text { Standardized } \\
\text { Coefficients }\end{array} \\
\text { Beta }\end{array}$} & \multirow[t]{2}{*}{$\mathbf{t}$} & \multirow[t]{2}{*}{ Sig. } \\
\hline & & $\mathbf{B}$ & $\begin{array}{c}\text { Std. } \\
\text { Error }\end{array}$ & & & \\
\hline \multirow[t]{4}{*}{1} & (Constant) & -.327 & 1.438 & & -.227 & .821 \\
\hline & Komitmen organisasional & -.013 & .041 & -.045 & -.331 & .742 \\
\hline & Lingkungan kerja & .051 & .053 & .114 & .953 & .344 \\
\hline & Kepuasan kerja & .041 & .050 & .110 & .816 & .417 \\
\hline
\end{tabular}

Sumber: Data diolah, 2018

Tabel 10. menunjukkan bahwa nilai sigifikansi dari variabel Komitmen organisasional sebesar 0,742, lingkungan kerja sebesar 0,344, dan kepuasan kerja sebesar 0,417. Nilai diatas lebih besar dari 0,05 yang berarti tidak ditemukan pengaruh antara variabel bebas. Dengan demikian, model yang dibuat tidak mengandung gejala heteroskedastiisitas.

Tabel 11.

Hasil Uji F

\begin{tabular}{llrrrrr}
\hline Model & & Sum of Squares & df & \multicolumn{1}{c}{$\begin{array}{c}\text { Mean } \\
\text { Square }\end{array}$} & F & Sig. \\
\hline 1 & Regression & 188.778 & 3 & 62.926 & 24.737 & $.000^{\text {a }}$ \\
& Residual & 180.608 & 71 & 2.544 & & \\
& Total & 369.387 & 74 & & & \\
& & & & &
\end{tabular}

Sumber: Data diolah, 2018

Hasil pengujian yang ada di Tabel 11 memperlihatkan nilai $\mathrm{F}$ hitung sebesar 24,737 dengan nilai signifikansii $\mathrm{P}$ value 0,000 yang lebih kecil dari $\alpha=0,05$, ini berarti model yang digunakan pada penelitian ini adalah layak. Hasil ini memberikan makna bahwa ketiga variabel bebas yaitu Komitmen organisasional, 
lingkungan kerja, dan kepuasan kerja tepat memproyeksikan fenomena turnover intention pada karyawan Koperasi Pasar Srinadi. Hal ini menunjukkan arti model dapat digunakan untuk analisa lebihlanjut

Berdasarkan hasil uji regresi linear berganda, bahwa hasil analisis pengaruh komitmen organisasional terhadap turnover intention diperoleh nilai Signifikansi sebesar 0,002 dengan nilai koefisien regresi negatif sebesar -0,203. Nilai Signifikansi $0,002<0,05$ mengindikasikan bahwa $\mathrm{H}_{0}$ ditolak dan $\mathrm{H}_{1}$ diterima. Hasil ini mempunyai arti bahwa Komitmen organisasional berpengaruh negatif dan signifikan terhadap turnover intention pada karyawan Koperasi Pasar Srinadi Klungkung.

Berdasarkan hasil uji regresi linear berganda, bahwa hasil analisis pengaruh lingkungan kerja terhadap turnover intention diperoleh nilai Signifikansi sebesar 0,000 dengan nilai koefisien beta $-0,319$. Nilai Signifikansi $0,000<0,05$ mengindikasikan bahwa $\mathrm{H}_{0}$ ditolak dan $\mathrm{H}_{2}$ diterima. Hasil ini mempunyai arti bahwa lingkungan kerja berpengaruh negatif dan signifikan terhadap turnover intention pada karyawan Koperasi Pasar Srinadi Klungkung.

Berdasarkan hasil uji regresi linear berganda, bahwa hasil analisis pengaruh kepuasan kerja terhadap turnover intention diperoleh nilai Signifikansi sebesar 0,000 dengan nilai koefisien beta $-0,288$. Nilai Signifikansi $0,000<0,05$ mengindikasikan bahwa $\mathrm{H}_{0}$ ditolak dan $\mathrm{H}_{3}$ diterima. Hasil ini mempunyai arti bahwa kepuasan kerja berpengaruh negatif dan signifikan terhadap turnover intention pada karyawan Koperasi Pasar Srinadi Klungkung.

Tabel 12.

Hasil Uji Koefisien Determinasi

\begin{tabular}{ccccc}
\hline Model & R & R Square & $\begin{array}{c}\text { Adjusted } \\
\text { R Square }\end{array}$ & $\begin{array}{c}\text { Std. Error of the } \\
\text { Estimate }\end{array}$ \\
\hline 1 & $0,715^{\mathrm{a}}$ & 0,511 & 0,490 & 10,59492 \\
\hline
\end{tabular}

Sumber: Data diolah, 2018

Hasil uji pada Tabel 12. memberikan hasil dimana diperoleh besarnya adjusted $\mathrm{R}^{2}$ (koefisien determinasi yang telah disesuaikan) adalah sebesar 0,490 mempunyai arti bahwa sebesar $49 \%$ variasi turnover intention pada karyawan Koperasi Pasar Srinadi Klungkung dipengaruhi oleh variasi Komitmen organisasional, lingkungan kerja, dan kepuasan kerja, sedangkan sisanya sebesar $51 \%$ djelaskan oleh faktor lain yang tidak dimasukkan ke dalam model.

Hasil perhitungan menyatakan komitmen organisasional mempunyai hubungan negatif dan signifikan terhadap turnover intention karyawan. Hasil ini sesuai dengan hipotesis satu $\left(\mathrm{H}_{1}\right)$ yang menyatakan bahwa komitmen organisasional mempunyai pengaruh negatif dan signifikan terhadap turnover intention.

Tingginya komitmen organisasaonal yang dirasakan karyawan akan mengurangi tingkat turnover intention karyawan pada Koperasi Pasar Srinadi Klungkung. Berdasarkan deskripsi variabel komitmen organisasional, karyawan merasa bangga bekerja di perusahaan, karyawan merasa termotivasi untuk berprestasi, karyawan ingin memajukan perusahaan, karyawan merasa bahwa nilai yang dianut perusahaan sudah sesuai dan karyawan bersedia untuk bekerja optimal 
untuk mencapai tujuan Koperasi Pasar Srinadi, ini menunjukkan rerata skor yang tinggi.

Hal ini memberikan petunjuk karyawan mempunyai komitmen organisasional yang tinggi pada perusahaan dan turnovr intention akan rendah. Temuan ini mendukung hasil penelitian yang dilakukan oleh Pratiwi \& Ardana (2015) dan Kharismawati \& Dewi (2016) yang menyatakan bahwa komitmen organisasional berpengaruh negatif terhadap turnover intention bahwa komitmen organisasional yang semakin tinggi akan mengakibatkan menurunnya turnover intention karyawan.

Khan et al. (2014) dan Abdurrahim \& Anisah (2015) mengemukkkan komitmen organisasional yang rendah menyiratkan indikasi peningkatan kemauan berpindah karyawan.. Sejumlah hal yang perlu diperhatikan dalam proses pengembangan rasa komitmen karyawan yakni, perusahaan wajib mengutamakan kenyamanan karyawan, terdapatnya komunikasi yang lancar antara karyawan terhadap sesama karyawan lainnya juga atasannya dan perusahaan menyediakan contoh dan inspirasiserta peluang berkarir di dalam perusahaan tersebut. Jehanzeb et al. (2013) yang menyatakan bahwa komitmen organisasional berpengaruh negatif dan signifikan terhadap turnover intention.

Hasil penelitian menyatakan lingkungan kerja mempunyai hubungan negatif dan signifikan terhadap turnover intention karyawan. Hasil ini sesuai dengan hipotesis dua $\left(\mathrm{H}_{2}\right)$ yang menyatakan bahwa lingkungan kerja berpengaruh negatif dan signifikan terhadap turnover intention. Lingkungan kerja yang baik atau nyaman yang dirasakan karyawan akan mengurangi tingkat turnover intention karyawan pada Koperasi Pasar Srinadi Klungkung.

Berdasarkan deskripsi variabel lingkungan kerja, karyawan merasa sudah disediakan kantin yang mudah dicapai, mendapatkan jaminan kesehatan, tersedianya kamar kecil, mendapatkan penerangan, suhu udara, pengendalian suara bising, warna ruangan, ruang gerak, keamanan yang sudah pas, dan merasa adanya hubungan baik antar karyawan ataupun hubungan karyawan dengan pemimpin pada Koperasi Pasar Srinadi, ini menunjukkan rata-rata skor yang tinggi.

Hal ini menunjukkan bahwa lingkungan kerja yang baik atau nyaman yang dirasakan karyawan akan mengurangi tingkat turnover intention karyawan. Qureshi et al. (2013) dalam penelitiannya lingkungan kerja memiliki pengaruh negatif dengan turnover intention, yang menunjukkan kondisi kerja yang baik dapat mengurangi jumlah turnover intention.

Hasil penelitian yang dilakukan oleh Chairani (2014) memperoleh hasil work environment mempunyai hubungan negatif terhadap turnover intention, lingkungan kerja yang buruk, dalam konteks kurang lengkapnya fasilitas yang diberikan pada karyawan, tidak tersediakannya tempat untuk beristiraht karyawan, akan menimbulkan niat karyawan untuk mengundurkan diri. Putra \& Utama (2017) dan Ngantung et al. (2015) lingkungan kerja berpengaruh negatif dan signifikan terhadap turnover intention.

Hasil penelitian menyatakan bahwa kepuasan kerja berpengaruh negatif dan signifikan terhadap turnover intention karyawan. Hasil ini sesuai dengan hipotesis tiga $\left(\mathrm{H}_{3}\right)$ yang menyatakan bahwa kepuasan kerja berpengaruh negatif dan signifikan terhadap turnover intention. Tingginya tingkat kepuasan kerja yang 
dirasakan oleh karyawan akan mengurangi tingkat turnover intention karyawan pada Koperasi Pasar Srinadi Klungkung.

Berdasarkan deskripsi variabel kepuasan kerja, karyawan merasa puas dengan pekerjaan itu sendiri, merasa mempunyai tanggung jawab dalam pekerjaannya, puas dengan gaji yang cukup, merasa senang ada kesempatan pengembangan karir, dan adanya hubungan antarsesama karyawan dan hubungan antara karyawan dan pemimpin yang harmonnis pada Koperasi Pasar Srinadi, ini menunjukkan rata-rata skor yang tinggi.

Hal ini menunjukan bahwa lingkungan kerja yang baik atau nyaman yang dirasakaan karyawan akan mengurangi tingkat turnover intention karyawan. Wisantyo \& Madiistriyatno (2015), Monica \& Putra (2017), Chiedu, Hapriza, \& Ashar (2017) menerangkan kepuasan kerja mempunyai pengaruh yang negatif terhadap turnover intention dan kepuasaan kerja mempunyai pengaruh yang negatif pada turnover intention. Kepuasan kerja mempunyai pengaruh yang negatif pada turnover intention.

Implikasi penelitian ini adalah menekankan pada manfaat nyata dari hasil penelitian untuk mampu meurunkan tingkat turnover intention karyawan dalam sebuah perusahaan khususnya pada Koperasi Pasar Srinadi Klungkung Beberapa implikasi dari hasil penelitian yang sudah dilakukan diantaranya adalah pertama, terbukti bahwa responden merasa adanya komitmen organisasional yang tinggi sehingga karyawan dapat menurunkan tingkat turnover intention karyawan . Oleh karena itu, perusahaan harus mampu mempertahankan karyawan, karena ketika tingkat komitmen organisasional tinggi, maka tingkat turnover intention karyawan menurun.

Kedua, terbukti bahwa responden merasakan adanya kenyamanan dan keamanan lingkungan kerja yang tinggi di Koperasi Pasar Srinadi Klungkung. Hal ini menimbulkan adanya tingkat turnover intention yang rendah dalam perusahaan, maka dapat meningkatkan keinginan karyawan untuk menetap di suatu perusahaan. Oleh karena itu, perusahaan harus menjaga dan memperhatikan lingkungan kerja sekitar yang diberikan kepada karyawan, agar dapat menurunkan keinginan karyawan untuk keluar dari perusahaan.

Ketiga, melalui penelitian ini juga terbukti bahwa responden merasa puas dalam bekerja dikarenakan perusahaan mampu memberikan kepuasan kerja dalam hal respon emosional terhadap situasi kerja, hasil kerja yang diperoleh, dan kepuasaan kerja mempresentasikan beberapa sikap yang merupakan sumber kepuasan. Oleh karena itu, perusahaan harus mampu mempertahankan keadaan dan kepuasan kerja karyawan, agar mampu menurunkkan keinginan karyawan yang berpikiran keluar dari tempat kerja.

Beberapa keterbatasan penelitian ialah hanya meneliti tentang beberapa variabel yaitu, komitmen organisasional, lingkungan kerja, dan kepuasaan kerja dalam mengukur turnover intention. Penelitian yang akan datang diharapkan dapat menambah jumlah variabel penelitian yang dipergunakan untuk mengetahui turnover intention, seperti: stres kerja, work family conflict, budaya organisasi, kompensasi, dan lainnya. 
Penelitian hanya memilih satu lokasi penelitian hanya di Koperasi Pasar Srinadi Klungkung. Penelitian yang akan datang diharapkan dapat mengembangkan dengan memilih lokasi lebih dari satu.

Sampel diambil dalam satu waktu tertentu (cross section) sedangkan lingkungan cepat berubah, sehingga penelitian ini penting dilakukan di masyarakat lainnya dengan menambahkan indikator pengaruh lainnya.

\section{SIMPULAN}

Komitmen organisiasional mepunyai pengaruh yang negatif dan signifiikan pada turnover intention. Hal ini menyiratkan tingkat komitmen organisassional tinggi di dalam perusahan maka tingkat turnover intention karyawan rendah. Lingkungan kerja memiliki pengaruh negatif dan signifikan terhadap turnover intention karyawan. Hal ini menunjukan bahwa ketika lingkungan kerja baik atau tinggi dalam perusahaan maka tingkat turnover intention karyawan rendah. Kepuasan kerja memiliki pengaruh negatif dan signifikan terhadap turnover intention karyawan. Hal ini menunjukan bahwa ketika tingkat kepuasan kerja tinggi di dalam perusahaan maka tingkat turnover intention karyawan rendah. Hasil analisis penelitian, pembahasan dan kesimpulan terdapat beberapa saran yang dapat digunakan sebagai bahan pertimbangan dalam menentukan kebijakan dimasa mendatang terutama yang berkaitan dengan komitmen organisaional, lingkungan kerja, kepuasan kerja, dan turnover intention.

Berdasarkan hasil penilaian karyawan Koperasi Pasar Srinadi Klungkung, pemimpin disarankan untuk dapat menurunkan ketertarikan karyawannya untuk mencari pekerjaan lainnya dan meningkatkan keinginan untuk menetap pada perusahaan dengan cara memotivasi karyawan, memberikan promosi jabatan, dan lain sebagainya. Hasil penilaian karyawan Koperasi Pasar Srinadi Klungkung, pemimpin disarankan untuk mengarahkan dan membina karyawannya agar dapat meningkatkan keinginan karyawan untuk tetap berada dalam perusahaan membuat karyawan berusaha untuk melaksanakan tugas upaya tujuan perusahaan tercapai. Memiliki tingkat komitmen organisasional yang tinggi, dapat menekan tingkat turnover intention karyawan.

Hasil penilaian karyawan Koperasi Pasar Srinadi Klungkung, pemimpin disarankan untuk memperhatikan dan meningkatan pelayanan-pelayanan yang diberikan kepada karyawan, seperti pelayanan jaminan kesehatan, tempat untuk makan atau kantin, menyediakan kamar mandi atau toilet dalam perusahaan dan menciptakan kondisi kerja yang baik, dalam penerangan, suhu udara, dan keamanan kerja bagi karyawan. Memiliki tingkat lingkungan kerja yang tinggi, mampu menekan tingkat turnover intention karyawan. Hasil penilaian, pemimpin disarankan untuk meningkatkan kepuasan karyawan dalam pekerjaan itu sendiri, kepuasan pada gaji dan kepuasan kepada atasan untuk memberikan bantuan teknis dan dukungan prilaku kepada bawahan yang mengalami permasalahan dalam pekerjaan. Memiliki tingkat kepuasan kerja yang tinggi, dapat menekan tingkat turnover intention karyawan. 


\section{REFERENSI}

Abdurrahim, \& Anisah, H. U. (2015). Pengaruh Kepuasan Kerja Dan Komitmen Organisasi Terhadap Turnover Intention Karyawan (Studi Pada Pt. Bank Perkreditan Rakyat Mitratama Arthabuana). Jurnal Wawasan Manajemen, 3(3), 191-204.

Bramantara, B., \& Dewi, K. (2015). Pengaruh Kepuasan Kerja dan Komitmen Organisasi Terhadap Turnover Intention Karyawan Pada Krisna Oleh - Oleh Khas Bali III. Jurnal Ilmu Manajemen, 4(1), 1-20.

Chairani, H. (2014). Pengaruh Komitmen Organisasional, Kepuasan Kompensasi, Kepuasan Kerja, dan Lingkungan Kerja terhadap Turnover Intention pada PT XYZ Tbk. Bakrie Univercity.

Chiedu, C. K., Hapriza, C. S. L., \& Ashar, H. B. (2017). The Relationship Among Job Satisfaction, Oreganizational Commitiment and Employees' Turnover at Unilever Corporation in Nigeria. European Journal of Multidisciplinary Studies, 83(8), 370-383.

Gillies, D. . (1989). Manajemen Keperawatan: Suatu Pendekatan Sistem Edisi 2. Illionis: WB Saunders Company.

Handaru A. W., \& Muna, N. (2012). Pengaruh Kepuasan Gaji Dan Komitmen Organisasi Terhadap Intensi Turnover. Jurnal Riset Manajemen Sains Indonesia (JRMSI), 3(4), 1-12.

Jehanzeb, K., Rasheed, A., \& Rasheed, M. . (2013). Organizational Commitment and Turnover Intention: Impact of Employee's Training in Private Sector of Saudi Arabia. International Journal of Business \& Management, 8(8), 79-90.

Khan, I., Allah, N., Shadiullah, K., Farhatullah, K., Sahib, K., \& Naseem, B. Y. (2014). The Impact of Organizational Commitment on the Intention to Leave among the Academicians in Higher Educational Institutions in Pakistan. International Journal of Academic Research in Business and Social Sciences, 4(2), 2222-6990.

Kharismawati, \& Dewi, M. (2016). Pengaruh Komitmen Organisasional, Dukungan Sosial, Dan Iklim Etika Terhadap Turnover Intention. E-Jurnal Manajemen Unud, 5(2), 2302-8912.

Mahdi, A. F., Mohamad, Z. M. M. N., Asmadi, A. S., \& Sulaiman, A, A. N. (2012). The Relationship Between Job Satisfaction and Turnover Intention. American Journal of Applied Sciences, 9(9), 1518-1526.

Monica, \& Putra, S. (2017). Pengaruh Stres Kerja, Komitmen Organisasional, Dan Kepuasan Kerja Terhadap Turnover Intention. E-Jurnal Manajemen Unud, 
6(3), 2302-8912.

Ngantung, G. R., Saerang, D. P. E., \& Pandowo, M. (2015). The Effect Of Job Stress, Workload And Work Environment On Employee Turnover (Case Study At Pt Hasjrat Abadi Manado). Jurnal Berkala Ilmiah Efisiensi, 15(5), $1-12$.

Nilesh, T. (2015). Organizational Commitment and Turnover Intention in BPO ITES and Retail Sector Employees. Journal of Phychosocial Research, 10(1), 89-98.

Pratiwi, I. Y., \& Ardana, I. . (2015). Pengaruh Stres Kerja dan Komitmen Organisasional Terhadap Intention to Quit Karyawan Pada PT. BPR Tish Batubulan. E-Jurnal Manajemen Unud, 4(7), 2036-2051.

Putra, I. . D., \& Utama, M. (2017). Pegaruh Lingkungan Kerja dan Kepuasan Kerja terhadap Turnover Intention di Mayaloka Villa Seminyak. E-Jurnal Ekonomi Dan Bisnis Universitas Udayana, 6(9), 1-20.

Qureshi, M. I., Iftikhar, M., \& Abbas, S. G. (2013). Relationship Between Job Stress, Workload, Environment and Employees Turnover Intentions: What We Know, What Should We Know. World Applied Sciences Journal, 23(6), 1818-4952.

Rarasanti, I. A. P., \& Suana, I. W. (2016). Pengaruh Job Embeddedness, Kepuasan Kerja, dan Komitmen Organisasional Terhadap Turnover Intention Karyawan. E-Jurnal Manajemen Unud, 5(7), 4690-4718.

Salleh, R., Mishaliny, S. ., \& Haryani, H. (2012). Job Satisfaction, Organizational Commitment and Turnover Intention: A Care Study on Employees of a Retail Company in Malaysia. World Academy of Science, Enginering and Technology, 1(1), 316-322.

Susila Putra, I. P. D. S., \& Suana, I. W. (2016). Pengaruh Perceived Organizational Support dan Komitmen Organisasional Terhadap Turnover Intention Karyawan. E-Jurnal Manajemen Unud, 5(10), 6260-6287.

Sutanto, E. M., \& Gunawan, C. (2013). Kepuasan Kerja, Komitmen Organisasional dan Turnover Intentions. Jurnal Mitra Ekonomi Dan Manajemen Bisnis, 4(1), $1-12$.

Widodo, R. (2010). Analisis Pengaruh Keamanan Kerja dan Komitmen Organisasional terhadap Turover Intention serta Dampaknya pada Kinerja Karyawan Oursourcing (Studi pada PT.PLN Persero APJ Yogyakarta). Universitas Diponegoro. 
Widyadmono, V. M. (2015). Pengaruh Kepuasan Kerja Dan Komitmen Organisasi Terhadap Turnover Intention (Studi pada Accounting Staff Perusahaan Swasta di DIY). Jurnal Manajemen Indonesia, 15(2), 1-12.

Widyantara, I. B. P., \& Ardana, I. K. (2015). Pengaruh Kepuasan Kerja Dan Komitmen Organisasi Terhadap Intensitas Turnover Karyawan. E-Jurnal Manajemen Unud, 4(6), 1670-1683.

Wisantyo, N. I., \& Madiistriyatno, H. (2015). Pengaruh Stres Kerja, Disiplin Kerja dan Kepuasan Kerja terhadap Intensi Turnover (Studi pada Lembaga Pengelola Dana Bergulir Koperasi danUsaha Mikro, Kecil dan Menengah). Jurnal MIX, 5(1), 1-20.

Youcef, S., Ahmed, S. S., \& Ahmed, B. (2016). The Impact of Job Satisfaction on Turnover Intention by the Existence of Organizational Commitment, and Intent to Stay as Intermediates Variables Using approach PLS in Sample Worker Department of Transport Saida. Journal Management, 6(6), 198202. 